[Chem. Pharm. Bull.

34( 9$) 3933-3935(1986)$

\title{
Enzyme-Linked Immunosorbent Assay for Several Mannans
}

\author{
Takeshi Mikami, ${ }^{a}$ Shigeo Suzuki,${ }^{b}$ Conrad Schuerch, ${ }^{c}$ \\ and MASUKo SUZUKI*a \\ Department of Microbiology ${ }^{a}$ and Second Department of Hygienic Chemistry, ${ }^{b}$ \\ Tohoku College of Pharmacy, 4-4-1 Komatsushima, Sendai 983, Japan and \\ School of Environmental Science and Forestry, ${ }^{c}$ New York \\ State University, Syracuse, New York 13210, U.S.A.
}

(Received February 27, 1986)

\begin{abstract}
Applications of polysaccharide antigens for enzyme linked immunosorbent assay (ELISA) were investigated. Two types of yeast mannan with or without branches and two synthetic linear mannans were examined for adsorbability on a polystyrene microtiter plate from a solution in $0.06 \mathrm{M}$ bicarbonate-carbonate buffer $(\mathrm{pH} 9.6)$. Upon treatment with rabbit anti-mannan antibody, peroxidase-conjugated anti-rabbit immunoglobulin $\mathrm{G}$ antibody, and $o$-phenylenediamine plus hydrogen peroxide, the intensity of color in a microtiter plate pretreated with the mannans was linearly proportional to the concentration of these mannans.
\end{abstract}

Keywords-Saccharomyces cerevisiae; polysaccharide; yeast mannan; synthetic linear mannan; enzyme-linked immunosorbent assay; ELISA

Solid phase immunoassay is a useful technique for the determination of antigens or antibodies in body fluids. Polystyrene beads, red blood cells, and agarose beads have been used as carriers, on the surface of which the antigen-antibody reactions take place. ${ }^{1-3)}$ However, the use of a polystyrene microtiter plate instead of these minute beads seems to be preferable for the quantitative determination of antigens and/or antibodies. ${ }^{4)}$ Because many protein antigens bind to the surface of a polystyrene plate through hydrophobic bonds, ${ }^{5}$ ) various papers dealing with enzyme-linked immunoassay of these antigens have been published in the past decade. ${ }^{6,7)}$ However, few papers have been published on enzyme linked imunosolvent assay (ELISA) of polysaccharide antigens, because of the poor adsorbability of simple polysaccharides on a polystyrene surface. In the present study, we report a method of ELISA with anti-polysaccharide antibodies.

\section{Materials and Methods}

General-_-Polystyrene 96-well EIA microplates (non-irradiated) purchased from Linbro (cat. no. 76-381-04) were used for the assay. o-Phenylenediamine was obtained from Wako Junyaku Ltd., Osaka, Japan.

Mannans - The neutral subfraction of mannans of Saccharomyces cerevisiae wild type strain (baker's yeast) and $S$. cerevisiae X2180-1A-5 mutant strain, designated as WNA and MNM, respectively, were prepared and purified by the same method as used in previous studies. ${ }^{89}$ ) Total carbohydrate contents of WNM and MNM determined by the modified Molisch method were 96.0 and $93.0 \%$, respectively. Neither phosphorus $(<0.0 \%)$ nor nitrogen $(<0.3 \%)$ was detected in these polysaccharides. Synthetic mannans, poly- $\alpha-\left(1 \rightarrow 6^{\prime}\right)$-anhydro-D-mannopyranose $(\operatorname{SLM} \alpha 1 \rightarrow 6)$ and poly- $\alpha-\left(1 \rightarrow 3^{\prime}\right)$-anhydro-D-mannopyranose $(\operatorname{SLM} \alpha 1 \rightarrow 3)$ were prepared by the reported methods. ${ }^{10)}$

Antisera-Antisera were prepared according to Okubo et al. ${ }^{11}$ by immunizing rabbits with heat-killed whole cells of baker's yeast. The antiserum had an agglutinin titer of $1: 2560$ against the immunizing cell suspension and showed a high precipitin activity against the mannan subfractions. Peroxidase-conjugated goat anti-rabbit immunoglobulin G (IgG) was purchased from Miles-Yeda Co., Rehovot, Israel.

ELISA Protocol Used to Detect Antibodies to Polysaccharides_- The method was essentially the same as that 
described by Wilson and Hearn. ${ }^{12)}$ Namely, $100 \mu$ l of polysaccharide solution in $0.06 \mathrm{M}$ bicarbonate-carbonate buffer (pH 9.6) containing mannans, $10 \mathrm{mg} / \mathrm{ml}$, was added to wells, and the plate was left at room temperature (about $20^{\circ} \mathrm{C}$ ) overnight. The plate was washed thoroughly with $0.01 \mathrm{M}$ phosphate-buffered saline containing $0.05 \%$ Tween 20 (PBS/TW, pH 7.2), three times ( $20 \mathrm{ml}$ each). Then, $100 \mu \mathrm{l}$ of PBS/TW containing $1 \%$ bovine serum albumin was added to each mannan-sensitized well and the plate was left for $2 \mathrm{~h}$ at room temperature. The plate was washed three times with PBS/TW $(20 \mathrm{ml}$ each), then anti-serum, $100 \mu \mathrm{l}$, was added to each well, and the plate was left at room temperature for $2 \mathrm{~h}$, then washed again. Diluted peroxidase-goat anti-rabbit IgG antibody conjugate (100 $\mu \mathrm{l})$ was added to each well, and the plate was left at room temperature for $2 \mathrm{~h}$, then washed 3 times with PBS/TW. A substrate solution was prepared by dissolving $20 \mathrm{mg}$ of $o$-phenylenediamine in $1 \mathrm{ml}$ of methanol solution and $99 \mathrm{ml}$ of $0.15 \mathrm{M}$ citrate buffer ( $\mathrm{pH} 5.0$ ), and $0.1 \mathrm{ml}$ of $3 \% \mathrm{H}_{2} \mathrm{O}_{2}$ was added immediately before use. A $100 \mu$ l aliquot of substrate solution was added to each well, and the plate was left in the dark at room temperature for $30 \mathrm{~min}$. Then $100 \mu \mathrm{l}$ of $2 \mathrm{~N}$ $\mathrm{H}_{2} \mathrm{SO}_{4}$ was added to each well, and the absorbance at $492 \mathrm{~nm}$ was estimated by using an Immuno-reader RJ-2000 (Intermed Co., Tokyo, Japan).

\section{Results and Discussion}

ELISA is an important new technique. The adsorption of soluble antigen on the solid phase is a major factor governing the sensitivity and precision of the assay, so the choice of carrier is an important aspect of quality control. Figure 1 shows calibration curves for mannans obtained by using the ELISA method. A linear proportionality was observed between color intensity and concentration of SLM $\alpha(1 \rightarrow 3)$ or WNM in the range from 32 to $128 \mu \mathrm{g} / \mathrm{ml}$, when 100 -fold-diluted antiserum was used, and the use of more diluted antiserum resulted in corresponding changes of the linear response range (data not shown). Crossreactivity between WNM and SLM $\alpha(1 \rightarrow 3)$ was high, but MNM and SLM poly- $\alpha\left(1 \rightarrow 6^{\prime}\right)$ showed only weak reactivity. Thus, the antiserum was able to detect mainly $\alpha\left(1 \rightarrow 3^{\prime}\right)$ mannopyranosyl linkages. The above results also indicate that these simple polysaccharides, such as WNM, MNM, SLM $\alpha(1 \rightarrow 6)$, and $\operatorname{SLM} \alpha(1 \rightarrow 3)$, are adsorbed on a polystyrene plate.

The mechanism of adsorption of antigen on a plastic surface is considered to be a nonspecific physical adsorption, probably based on hydrophobic interactions between proteins and the polystyrene surface. It is not known whether a particular portion of the antigen molecules is preferentially adsorbed. According to McLaren et al. ${ }^{13)}$ the binding of protein occurs in two stages. The initial adsorption is first order with respect to protein concentration and has a binding rate constant some 200 times greater than the second pseudo-first order phase of adsorption.

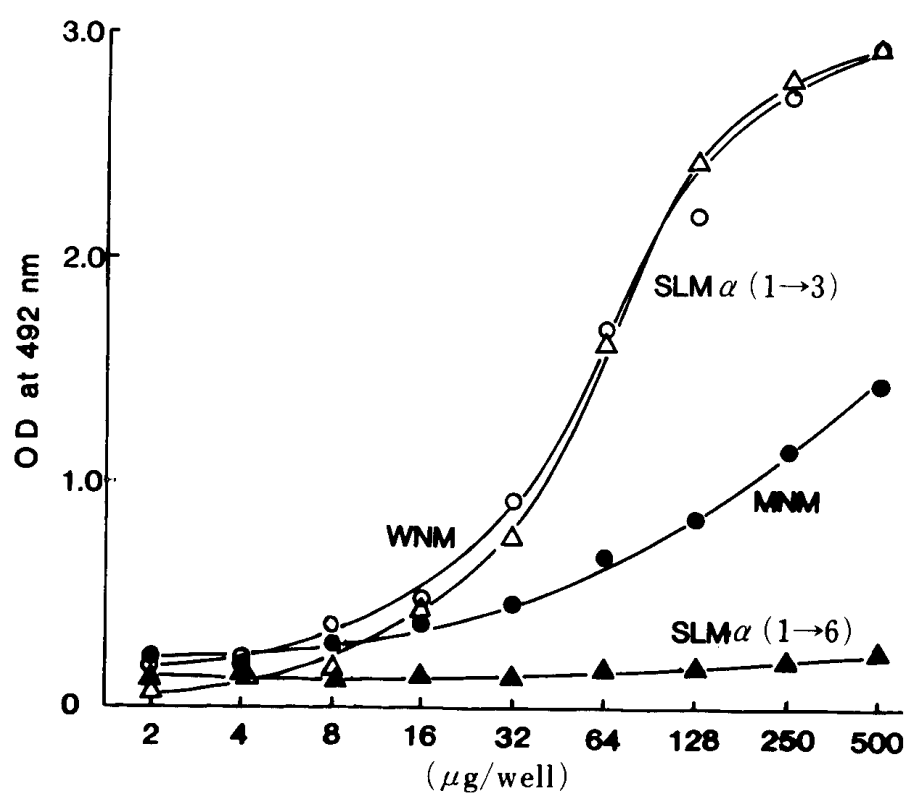

Fig. 1. Calibration Curves for Several Mannans Against Anti-S. cerevisiae Wild Type Strain Serum

The anti-serum was diluted $1: 100 . \bigcirc, W N M$; $\mathrm{MNM} ; \triangle$, SLM $\alpha(1 \rightarrow 3) ; \Delta, \operatorname{SLM} \alpha(1 \rightarrow 6)$. 
On the other hand, polysaccharide antigens tend to be adsorbed less well on polystyrene plates, and pretreatment of the plastic surface is often necessary. For example, Kelsoe and Weller ${ }^{14)}$ have described the use of poly-L-lysine to increase the uptake of polysaccharide antigens and have found this to provide reproducible results. They used a negatively charged polysaccharide from the trematode Schistosoma mansoni as an antigen, and showed that it could bind noncovalently to the surface of poly (L-lysine)-coated wells in polystyrene trays, but not directly to polystyrene. They used phosphate buffered saline, $\mathrm{pH} 7.2$, and a concentration of $200-400 \mu \mathrm{g} / \mathrm{ml}$ of antigen. However, in this work, we observed direct adherence of a polysaccharide, mannan, to the polystyrene test plate. The main differences between their method and ours are the types of polysaccharide and the buffers employed. We investigated the relationship between the adherent amount of polysaccharide and the $\mathrm{pH}$ of the carbonate buffer. The adherent amount of polysaccharides increased with increasing buffer $\mathrm{pH}$. However, since excessively high $\mathrm{pH}$ may degrade the antigens, we chose a buffer $\mathrm{pH}$ of 9.6 , and a concentration of the antigen of up to $5 \mathrm{mg} / \mathrm{ml}$.

The application of the ELISA method to polysaccharides as described here is very simple and sould be useful for analysis of large numbers of samples, especially in connection with hybridization of cells for producing monoclonal antibody or genetic engineering procedures.

Acknowledgment The authors wish to thank Prof. D. W. R. Mackenzie, Dr. V. Hearn, and Mrs. Wilson, PHLS Mycological Reference Laboratory, London School of Hygiene and Tropical Medicine, London, U.K. for valuable advice.

\section{References}

1) E. Engvall, K. Jonsson, and P. Perlmann, Biochim. Biophys. Acta, 251, 417 (1971).

2) A. M. Deelder and J. G. Steefkerk, Ext. Parasitol., 37, 405 (1975).

3) P. A. Greenberger and R. Patterson, J. Laboratory Clinical Med., 99, 288 (1983).

4) R. Sepulveda, J. L. Longbottom, and J. Pepys, Clinical Allergy, 9, 359 (1979).

5) M. L. McLaren, J. E. Lillywhite, and A. C. S. Au, Medical Laboratory Sciences, 38, 245 (1981).

6) K. Holmberg, M. Berdischewsky, and L. S. Young, J. Infect. Dis., 141, 656 (1980).

7) R. A. Mantyjarvi, P. Jonsilahti, and M.-L. Katila, Clinical Allergy, 10, 187 (1980).

8) T. Nagase, T. Mikami, S. Suzuki, C. Schuerch, and M. Suzuki, Microbiol. Immunol., 28, 997 (1984).

9). T. Mikami, T. Nagase, T. Matsumoto, S. Suzuki, and M. Suzuki, Microbiol. Immunol., 26, 403 (1982).

10) F. Kong and C. Schuerch, Carbohydr. Res., 112, 141 (1983).

11) Y. Okubo, T. Ichikawa, and S. Suzuki, J. Bacteriol., 136, 63 (1978).

12) E. V. Wilson and V. M. Hearn, Sabouraudia, 21, 195 (1983).

13) M. L. McLaren, C. C. Draper, J. M. Roberts, E. Minter-Goedbloer, C. H. Teesdale, M. A. Amin, A. B. S. Omer, A. Bartlett, and A. Voller, Ann. Trop. Med. Parasitol., 72, 243 (1978).

14) G. H. Kelsoe and T. H. Weller, Proc. Natl. Acad. Sci. U.S.A., 75, 5715 (1978). 